\title{
Continuous Professional Development of Secondary School Teachers through Peer Observation: Implications for Policy \& Practice
}

\author{
* Jan Alam, PhD Scholar \\ ** Syed Muhammad Aamir, PhD Scholar \\ *** Dr. Saqib Shahzad: Chairman / Associate Professor
}

\begin{abstract}
This qualitative action research study aimed to examine teachers' perceptions about peer observation as an instrument for their Continuous Professional Development (CPD). For this purpose, the experiences of 12 purposefully selected secondary school teachers were captured through peer observation tool followed by focus group interviews to answers two research questions i.e. do teachers perceive peer observation as an effective instrument for their continuous professional development; and what are the merits and demerits in seeking sound professional development through peer observations? The conclusion reveals that peer observation was viewed by teachers as a valuable tool for their professional growth. Teachers reported that peer observation allowed them less anxiety, hesitation and pressure during teaching making the process more reliable and authentic. However, participants also reported time factor and less experience in observation on the part of teachers as obstacles to peer observation. The study includes some suggested recommendations for a more improved peer observation program.
\end{abstract}

Keywords: Shift towards democratic trends, peer observation, continuous professional development

\section{Introduction}

According to Dreyfus (1989), the significance of professional development programs for staff-training of an organization lies in the sense that they focus to enable them accomplish their career goals and avail the future opportunities successfully. In teaching profession which may be traced to as back as the age of Confucious (561 B.C.), its importance may not be denied. In this regard, Dreyfus suggests that the administration should first identify skill gaps of the staff and then determine arrangement of skill development programs so that these

\footnotetext{
*Beijing Normal University, China. Email: janalam@ mail.bne.edu.cn

**Department of Education, Abdul Wali Khan University Mardan, KP, Pakistan. Email: syed334@ hotmail.com

*** Chairman / Associate Professor, Department of Education, Abdul Wali Khan University Mardan, KP,

Pakistan. Email: professorsaqib77@gmail.com
} 
gaps are filled and their staff's professional growth is ensured. This may be a step towards maximizing the human capital. Having said that, the formalization of proper professional development of teachers' dates back to the early 1940s when teacher shortages were a direct result of World War II and was exasperated by the birth of the baby boom generation; remedying the issue of unqualified and uncertified teachers was the basic goal of professional development (Harris, 2004). However, currently, the focus of professional development programs is to improve teachers' performance through a collaborative approach which highlights that teachers may develop themselves professionally if they continue to support each other and work collaboratively (Blanchard et al, 2018).

According to Day (2013), a school professional development program (PDP) should encompass all the planned and conscious activities and learning experiences which may focus on benefitting teachers directly or indirectly so as to improve their teaching skills. In this regard, Elmore (2004) states that in traditional professional development programs (PDPs) teachers receive information during workshops and seminars from the experts they don't know. They are then required to display that knowledge in isolation during their interaction with students in the classroom. Similarly, Schmoker (2006) posits that there is an absence of the context in such workshops and thus teachers are deprived of the opportunity to engage in useful discussion about the problems they face in the natural setting. Moreover, individual needs of teachers are not redressed in an appropriate manner because they have no opportunity to reflect on their own as well as observe their colleagues' performance. Learning from one another in natural setting which is so important for ongoing professional development, is often missing in such traditional training programs. Secondly, teachers have no opportunities to transfer the information into practice they got from the trainers etc. Thirdly, the absence of context and mutual participation in such trainings create a lack of transfer of meaningful information and strategies among colleagues of the same rank and status.

Likewise, during the evaluation period of the workshops teachers' are assessed to determine to what extent they have digested the training instructions. They are given feedback on the basis of the assessment. Teachers try to practice in isolation the instruction given in the feedback during instruction. However, this isolation is devoid of the opportunity to work and learn in collaboration in the natural setting; this makes learning superficial in nature (Fullen, 2008). For example, in traditional PDP, a supervisor or a resource person with authority is assigned the duty to attend a teacher's class, observe him during instruction and 
provide feedback of an evaluative nature; thus, it might be a means of anxiety for the teacher being observed. This anxiety on the part of teacher might hinder his/her way to professional development (Day, 2013).

On the contrary, if teachers are assigned equal responsibilities to develop their professional competence by making them equal partners in the program; it may have tremendous benefits. They may be assigned the duty to conduct the observation process themselves instead of doing it by a person who is not the part of the academic staff in the school where the program is in practice. For example, in peer observation, both the teachers (the observer and the observed) are on democratic terms. The one being observed doesn't consider himself under any anxiety or authoritative pressure because of the feeling that it is his colleague who is observing him. Thus, according to Richards and Farrell (2005), such a practice might help them learn from each other; hence, enabling them to have a more insightful approach in their professional development. That is why according to Fullen, (2008), authentic professional development occurs only then when individuals are observed and engaged through learning experience in the natural setting. Dewey (2001) has called this natural setting experience as direct experience which might be gained through first hand contacts with the colleagues. Additionally, learning in the context makes an individual share ideas and information on a mutual and democratic basis without the pressure and anxiety of the authority or supervision.

Professional development programs may be useful and effective only when they allow teachers and participants to share and exchange fruitful ideas and views on mutual basis and involve them in reflection about their instructional skills. In this regard, a number of researchers like Desimone, (2009 \& 2011); Guskey and Yoon, (2009); and Timperley, Wilson, Barrar, and Fung, (2007) consider collaboration to be an important feature of teachers' professional development. Peer observation is a useful tool to seek such collaboration in the Continuous Professional Development (CPD) of teachers (Rees, et al. 2015). In this respect, a system of professional development is direly needed embedded with peer observation as an operational tool for continuous professional development (CPD) of our teachers in a systematic way and on democratic grounds towards best instructional practices in the field.

\section{Traditional (De-contextualized) Approach to Professional Development}

These professional development programs focused at teaching strategies to fulfill the developmental programs of the school rather than the learning of the participants and the 
topics presented there, were very much different from actual classroom setting (Kelchtermans, 2004; Liebermann, 1995). According to Parks, et al. (2007) the traditional approach to professional development is the teaching improvement that happens in an up and down fashion from an expert in the field down to the teacher, in which the information is infused into the practitioner. With this process, the idea is that new educational practices are developed into generic guidelines, taught in a quick 3-8 hour workshops, with the assumption that teachers will make a contextual connection to the context in which they teach. This model may be explained further that the workshops, where a teacher is removed from his classrooms, are valuable, while working in authentic learning situations collaboratively with peers is not (Liebermann, 1995).

\section{Contextualized Approach to Professional Development}

In reaction to the said traditional professional development approach a new trend is being emerged focusing on collaborative approach as a key in professional development programs (DuFour, et al. 2008). This approach emphasizes on working together that promotes learning in context towards professional development as is done in a peer observation model. Peer observations as a tool to advocate contextual professional development, may be linked to Dewey (2001) who intrinsically supported this model when he affirmed that natural first-hand experience in context has important connotation for teachers' professional development. In addition, Herbart (1896) and Friere's (2000) philosophy proposed that teachers best learn during their engagement with students which bypasses the perception that the teacher is the spring of knowledge and that he knows all. In this regard according to Fullan (2008) and Senge (2006), collaborative learning in context develops a systemic association that has the possibility to keep up with the changing situations through multiple dimensions. Presently, the use of peer observation has been the focus of research to use it for promoting the concept of learning in context. In this regard, Zwart, et al. (2007 \& 2008) have conducted two research studies (qualitatively as well as quantitatively) which have revealed the important role played by peer observation in teachers' professional development.

Having said that, the study aims to conduct a qualitative action research study and explore how continuous professional development of secondary school teachers may be accomplished through peer observation and in thus determine implications for its practice and policy recommendations accordingly.

The following research questions were framed accordingly; 
1. Do teachers perceive peer observation as an effective instrument for their continuous professional development?

2. What are the merits and demerits in seeking sound professional development through peer observations?

\section{Methodology}

This Action Research study followed qualitative action research design. According to Ferrance (2000), action research allows both the teachers and researchers to get involved in the process of conducting research, engage collaboratively and conduct data collection in their working environment. McNiff (2017) affirms that action research highlights the need for collaboration and group inquiry to collect information about social issues in order to develop action plans to solve these problems. In education, action research is the researcher's use of a systemic process to solve problems and make improvements in the programs practiced within the premises of the institution (Tomal, 2010).

When looking at my research questions, action research is an appropriate design since it involves views from actual participants of the study. Since action research is participant directed, it allows the participants to collaboratively reflect and identify problem under study. This step is important for educators so that they can examine where they are and how they can work collectively. Again, this study is an authentic school-based problem, with participants reflecting on how they can function collectively and collaboratively to improve CPD (Stringer, 2007; Tomal, 2010).

\section{Participants and Site}

This study was conducted at the three school campuses ( 2 boys' section and 1 girls' section) of Allied Institute of Management and Sciences, Mardan. For this purpose, after discussions with the heads of these three schools, 12 secondary school teachers ( 8 from boys' sections and 4 from girls' school) were purposefully selected on the basis of their level of experience to participate in the study. Moreover, the 12 participants were divided in 3 groups (1 Group having 4 teachers from each school); thus Group 1 represented teachers from Girls' Section and Group 2 and 3 represented teachers from Boys' Section 1 and 2 respectively. The rationale for the purposeful selection of the said research site and participants is that it was much convenient for us (research colleagues) to have access to them, carry out research activities and give practical shape to our research plan. This convenience could be seen in the fact that all the school campuses could be accessed in just 5 or 7 minutes time. The justification for purposeful selection is the qualitative nature of the study. According to 
Creswell (2017), in qualitative studies, the researcher does not aim to generalize the findings to a population but to carry out an in-depth discovery of the experiences of the participants. The researcher himself acts as a data collection instrument as he involves with the participants during this process. However, during data analysis his role is that of a realist, as he describes the participants' experiences through their own perspectives by bracketing his preconceptions and tries to remain as objective as possible. Nonetheless, the participants were introduced with the partly-researcher's-self-developed peer observation tool and proper training was given about its application accordingly.

\section{Role of the Researcher}

Stringer (2007) states that the role of researcher in qualitative studies is that of a facilitator whose job is to get all the stakeholders involve in dealing with the problem under study and provide support in delineating a proper and effective solution to that.

Hence, my main roles included building a safe environment that is supportive of individual learning, where participants, including myself, can share information and take risks.

As the researcher, I along with my colleagues was the primary instrument to gather data by observation and focus group interviews. I had access to colleagues in conducting observations. My goal was to have participants provide valuable insight to the process of peer observations. The data collected might provide a complete understanding for this inquiry.

\section{Structure of Peer Observation}

Considering the demands and goals of the teachers involved in their institution, peer observation may be conducted in different ways. According to Gaies and Bower (1990), peer observation may be comprised three stages i.e. a pre-observation stage (consultation among participants), the actual observation stage (process of observation) and post-observation stage (discussion between the observer and the observed). These stages are discussed below in detail (see figure 1).

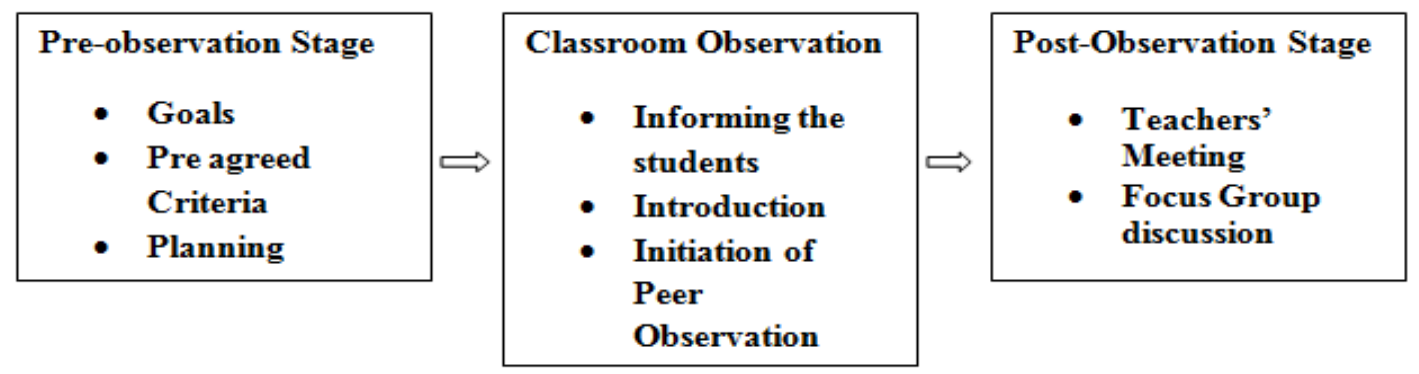

Figure 1. (Structure of Peer Observation) 


\section{Pre-observation Stage}

At this stage, the researchers had a meeting with the observer and the observed in each pair to discuss the ongoing planned observation. Richards and Lockhart (1991) posit that its purpose is mainly to plan what is to be observed, what would be the procedure and what materials are to be used.

\section{Classroom Observation}

At this stage, the researcher initiated the peer observation process letting the observer to conduct the actual observation already planned. According to Beigy and Woodin (1999), it may be a good practice to inform the students that their class may be observed by someone. They further suggested that the teacher who is going to be observed should make an introduction of the observer to the students; because this may help to reduce the possibility of any tense situation that may arise during observation. According to Richards and Lockhart, (1991) the observer should remain as neutral as possible as any involvement could compromise their ability to observe effectively.

All these considerations were put into practice during observation.

\section{Post-Observation Discussion}

The researcher conducted a post-observation discussion session for the participants in each pair collect their thoughts and determine what benefits the tool had for their professional development.

\section{Data Collection}

Being a qualitative study, the data collection instruments for this study included observations and focus group interview. The observation was carried out through peer observation tool partly developed by the researchers. This form was used by the participant teachers in pairs assisted by the researchers to observe each other during instruction. However, the principal instrument used for the collection of data was focus group interview. Morgan (1997) posits that in focus group the researcher first determines a topic and then the group members interact to collect data for it. As a qualitative method, focus groups have many of the same advantages as in-depth interviews in that they allow the researcher to interact directly with the participants, adjusting questions and eliciting more elaborate responses that may not be possible with a questionnaire (Nunan \& Bailey, 2009). During the focus groups, the researcher (as a moderator) asked questions that would elicit the participants' views of peer observation, including their thoughts on its benefits and limitations for both the observer and the teacher been observed. In this connection, the researcher carefully monitored the group 
discussion and made every attempt to formulate questions that were clear and open ended, adjusting them as appropriate to elicit explanations, descriptions, or illustrations. In addition, the researcher tried to keep questions consistent so that they could compare responses across the three groups. Additionally, it is worth pointing out that the researchers and the participants were colleagues, and therefore had a pre-established relationship with many of them; as peers, they exchanged opinions, shared ideas, and provided support for one another during the process (Corbin \& Strauss, 2008). Therefore, due to the mutual trust fostered through shared experiences among the stakeholders in the study, the participants shared their viewpoints honestly and freely.

\section{Process of Data Collection}

The researcher organized the 12 purposefully selected participant teachers in 3 groups further formulating each group into 2 pairs of participants (see figure 2). During the peer observation, each pair was asked to conduct observation of each other in turns using the peer observation as discussed above. These observations cycles were conducted weekly on a continuous basis for a month. Focus group interviews were conducted as soon as each peer observation cycle was completed. At the end of peer observation cycles, concluding focus session was held with the participants. The aim was to provide the group members a chance to interact collaboratively. The responses they gave were consisted of information that assisted towards the emergence of universal themes accordingly (Kennedy, et al. (2001).

\begin{tabular}{|c|c|c|c|c|c|}
\hline \multicolumn{6}{|c|}{ WEEK 1 - PEER OBSERVATIN CYCLE 1} \\
\hline \multirow{2}{*}{\multicolumn{2}{|c|}{$\begin{array}{c}\text { GROUP } 1 \\
4 \text { TEACHERS }\end{array}$}} & \multirow{2}{*}{\multicolumn{2}{|c|}{$\begin{array}{c}\text { GROUP } 2 \\
4 \text { TEACHERS }\end{array}$}} & \multirow{2}{*}{\multicolumn{2}{|c|}{$\begin{array}{c}\text { GROUP } 3 \\
4 \text { TEACHERS }\end{array}$}} \\
\hline & & & & & \\
\hline PAIR 1 & PAIR 2 & PAIR 1 & PAIR 2 & PAIR 1 & PAIR 2 \\
\hline TEACHER 1 & TEACHER 1 & TEACHER 1 & TEACHER 1 & TEACHER 1 & TEACHER 1 \\
\hline TEACHER 2 & TEACHER 2 & TEACHER 2 & TEACHER 2 & TEACHER 2 & TEACHER 2 \\
\hline & & & USCUS & & \\
\hline
\end{tabular}

\begin{tabular}{|l|}
\hline WEEK 2 - PEER OBSERVATIN CYCLE 2 \\
\hline WEEK 3 - PEER OBSERVATIN CYCLE 3 \\
\hline WEEK 4 - PEER OBSERVATIN CYCLE 4 \\
\hline
\end{tabular}

Figure 2. (Process of data collection) 


\section{Ethical Considerations}

Before commencement of the data collection process, the researchers contacted the school heads to request them allow their teachers participate in the study and to set up an initial meeting. During this meeting approval was sought so that their teachers may be permitted formally to participate in the proposed study. When this was done, they were provided with an informed consent letter notifying them of the purpose and procedure of the study. The institute and the participants were assigned pseudonyms in order to ensure their confidentiality. They had their choice to cancel their participation in the study at any point. They were also ensured that the results of the study would not be used for non-academic purposes.

\section{Data Analysis}

After the orderly transcription of the data collected mainly through the focus group discussions, the researchers carefully studied the data discussions using content analysis to identify the themes aligned with the research questions. Data analysis was initiated with open coding, that is according to Corbin and Strauss (2008, p.62), a procedure where "data are broken down into discrete parts, closely examined, compared for similarities and differences, and questions are asked about the phenomena as reflected in the data". As the researcher along with his co-researchers read the transcripts and labeled the phenomena, patterns began to emerge that allowed for the identification of categories. The next step was to look for codes of similar significance. The next stage included organization of codes (having similar nature) into a category system. Once the information was categorized, the themes identification was commenced and final themes were emerged. The process was concluded with sharing a hard copy of the findings with the participants to review for accuracy and credibility (Maxwell, 2007; Strauss \& Corbin, 1998; Stringer, 2007).

\section{Validity and Reliability}

According to Maxwell (2005) validity focuses to measure what is ought to be measured. Hence, for determining trustworthiness in the current study, I used multiple data techniques including a pre-observation interview with the participants in order to capture their prior perceptions of peer observations. Later on, their prolonged engagement in the peer observation process was consisted of a continuous weekly observation cycle with focus group interviews to collect their views regarding the challenges and success of the tool. After the focus group interviews, the researcher used member checking in order to review the data to 
ensure that it adequately represents their experiences. This also allowed for participants to identify any barriers that restrict their full participation in the study.

Similarly, reliability was ensured through inter-coder agreement (Guba \& Lincoln, 1985). The researchers coded the data independently and later on matched their codes. The similarity index was high; a little bit ambiguity that arose was generally in the wordings of the codes, the underlying concepts were mainly the same.

\section{Findings}

The verbal responses of the participants were analyzed through the process of content analysis and were organized around several emerging themes, broadly characterized as the perceived benefits and limitations of peer observation as a developmental tool. The themes that emerged from the focus groups in how the participants experience peer observation are discussed below;

\section{Peer Observation is a Valuable Tool for Professional Growth}

The participants all affirmed that peer observation was a worthwhile and valuable activity for their growth as professional teachers. Sub themes included observation leads towards learning, productive feedback, and collegiality.

\section{Observation Leads towards Learning}

The participants considered peer observation to be an opportunity to learn new approaches or strategies to incorporate into their own teaching practices. They claimed that this experience led them to make changes to their instruction, decreasing their talk time and having students complete more active learning tasks. One female participant remarked that it assisted her in building more variety into her instruction than she had done previously. She said:

I got used to teacher-orientated teaching, more lecturing and not integrating the students and so by observing these other teachers peer observation has become an additional opportunity for her to learn about the student-centered practices valued in the classroom.

In addition to modes of instruction, participants also focused on the way their colleagues matched certain strategies in order to facilitate communication.

Similarly, majority of the participants considered perceived peer observation as beneficial in that it allows them to address concerns, they have about teaching specific skills and to potentially remedy the weaknesses in their own instruction.

Some participants described that with regards to peer observation, watching colleagues helped them bridge the gap between the instructional practices they read about, or 
heard their teachers lecture on, and those that work best in the classroom. For them, narrowing the gap between theory and practice represented a significant advantage of watching other people teach. While both the observer and observed teachers gave equally rich insights into what they learned from their observations, it was the participants who observed talked about the value of observation in relation to their level of teaching experience. They felt that watching other teachers in the classroom helped build their confidence, especially when it came to the classroom management skills.

Similarly, most of the teachers in the focus group felt that the process assisted them in establishing useful discussions on teaching strategies. For example, a participant from focus group 2 said, "The colleague I worked with I got so many ideas. It was really positive. And I think that is the beauty of it. If you don't know somebody, then you can go in and think why I don't do that."

In addition, other participants highlighted the benefit of meeting the teacher they observed before or after the class so that they could have conversations about their teaching practices and other issues or concerns. That peer observation can help foster rapport between them. They understood its value as a developmental tool.

\section{Productive Feedback}

While the majority of the participants felt they had benefitted more as an observer than from being observed, some teachers shared their experiences of receiving feedback from the observers that was valuable in improving their instructional practices. They were very appreciative of the constructive feedback they received from those who observed her classes:

One of these participants also described an observation where the teacher approached him afterwards and shared comments about his lesson. Although the observer did not share any suggestions for improving the lesson, he was encouraged by the observers' informed comments about the way he paced his lesson and his use of materials. It helped him feel more confident about his approach to that particular class.

\section{Collegiality}

Collegiality refers to cooperative relationships among those who work together. A participant from senior boys' section mentioned the stresses of teaching classes and completing a graduate program at the same time, and how peer observation was an opportunity to get to know his colleagues and "go through this vulnerable stage together." This participant felt satisfied and easiness to have teachers observe him with whom he wanted to develop a professional relationship. He added that having the opportunities both to observe and be 
observed by others helped mitigate any discomfort that might be felt during the peer observation process:

I feel like we are all empathetic with each other or sensitive to each other's and respectful of each other's classroom because we have to be on both sides so we know what both sides feel like. I haven't had it affect negatively.

\section{There Are a Number of Limitations Connected to Peer Observation}

The participants' experience with peer observation led them to identify parts of the peer observation process that prevented them from reaping its benefits as a developmental tool. The sub themes that emerged from the focus groups in how participants felt limited by peer observation were time constraint and lack of experience of some teachers in observation skills.

\section{Time Constraint}

The participants have several considerations about time factor during peer observation. They felt that, despite its value, peer observation can sometimes feel like yet another task to be completed. Participants from girls' sections admitted that due to everyone's different schedules, it can be difficult to find time to communicate about the class they observe, either before or afterwards. They said:

If some teachers need to make time for other priorities, then they were faced with the possibility of other teachers to observe their classes after the break.

A participant from boys' section stated, "It can be a little annoying after when you get teacher having multiple observations to complete in a single term can also take up a significant amount of time".

\section{Lack of Experience}

In the case of observing their colleagues, participants were expected to contact the teacher in advance to arrange the observation and clarify expectations such as whether to introduce themselves or interact with the students etc. Several participants spoke about occasions when they have felt disappointed in the conduct of their peers, from showing up late to the classes they had arranged to observe or not showing up at all. A participant explained that he tried to have extra materials to give to the observer to help them follow the lesson, but sometimes this consideration is not reciprocated. He said:

I would rather feel very uneasy if an observer showed up unannounced to his class, comparing it to having his bedroom door open and someone just walking in: "I'm 
going to be like 'what do you think you doing here, this is my house'...it's like my own space with my students."

The use of this metaphor suggests that this participant sees his classroom as an intensely personal space and that an observation needs to proceed with the same courtesy you would extend to someone inviting you into their home. Similarly, a participant from girls' section was less uneasy at the thought of an unplanned observation, but spoke unfavorably of observers who interrupt her during class.

However, some participants commented that the researchers had already provided them with fruitful directions and some etiquette as guidelines for observation, but that individual teachers were failing to follow it. In any case, if the participants were to participate in and learn from peer observation, then politeness and consideration should be the primary concerns of the observing teacher. These were the practical obstacles to learning from peer observation.

\section{Discussion and Conclusions}

Classroom observation is an opportunity for a teacher to see how a peer manages his class and responds to the events that occur within that classroom. Overall, the participants' comments suggest that the peer observation system was beneficial for CPD of secondary school teachers in a number of ways. They felt that the peer observation system not only assisted in improving their teaching but it also helped in promoting fruitful discussion upon the instructional practices, ideas sharing and confidence enhancement. Many of the research studies on peer observations discuss such benefits of this model (Rees, et al. 2015; DiVall, et al. 2012; Shortland, 2010; Latz, et al. 2009).

Other studies that support the findings of the current study reveal that peer observation can function as a valuable developmental tool for both observers and observed teachers. For example, Bell (2001) posits that peer observation assists teachers to make improvements in their instructional practices and increase their repertoire of teaching strategies. In a study by Norbury (2001), the participants viewed peer observation as significantly improving the quality of teaching. Participants also found peer observation to be useful in offering fresh perspectives on familiar classroom routines. While both observers and observed teachers remarked on benefits in several studies, some studies revealed a greater emphasis on learning by watching a colleague. For example, in a quantitative study, Kohut, et al. (2007) revealed the perceptions of the observers who considered the peer observation process as influential in developing their own teaching contrary to improving the teaching of 
the observed teachers. In addition, one of the principal benefits of the peer observation process was the opportunity to watch a colleague leading their class (Bell \& Mladenovic, 2008). Similarly, Richards and Farrell's (2005) study also back our study results. He claims that peer observation may allow teachers to build a collegiality where the same or similar teaching concerns are shared and discussed, leading to mutual assistance. Many participants in Bell and Mladenovic's (2008) study also appreciated the opportunity to share best practices and work collaboratively by taking part in classroom observations. A study conducted by Adshead, White and Stephenson (2006) revealed that most of the teachers had positive views of peer observation as a developmental tool and considered it helpful in setting clearer learning goals with their students. However, they did not feel ready to commit to peer observation as it required time and the participation of another colleague.

Some studies that revealed indifferent or negative attitudes towards peer observation programs may be aligned with the second theme of the current study which highlights some limitations of peer observation like time constraint and lack of experience. In this respect, Chamberlain, D'Artrey and Rowe (2011) in their study on peer observation revealed that teachers were wary of peer observation as they felt it could be overly burdensome, with observation forms and records having to be submitted to those observing the process. Moreover, many participants felt there was ambiguity about the purpose of peer observation and therefore wanted clarification from the management. Similarly, according to Kohut, et al, (2007), and Adshead, et al, (2006) and Cosh (1999) when the implementation of peer observation was used in the school of Languages at Anglia Polytechnic University, many participants saw the model as threatening. Cosh (1999) states that the limitation with peer observation is that two colleagues may observe each other but with an uncritical attitude. He further states that people should be observed by at least two others so as to ensure objectivity in their feedback. His suggestions highlight that generally people are not only unqualified to judge their peers but also in many cases judge their peer subjectively. That is why; a reflective approach to encourage self-reflection and self-awareness about teachers' own teaching is reported to be the best way to increase capacity using peer observations (Cosh, 1999).

On the other hand, most of the research and literature to date has reported on ways peer observation is implemented, Hammersley-Fletcher and Orsmond (2004) report on the lack of attention that has been given to the process of the peer observation, and how to manage an integrated process to attain all the benefits. These authors suggest that if peer 
observations are not focused with clear goals, the process may thus be futile. Similarly, practitioners need the skills to be able to give constructive feedback of teaching in order for it to be professional development (Hammersley-Fletcher \& Orsmond, 2004).

To conclude it may be said that because of the larger benefits revealed by the current study findings and the research studies been cited, the use of peer observations can be a positive step towards professional development of teachers. It is a valuable tool for diagnosing and further clarification of an area in CPD that teachers may focus on. And it is this usefulness that enable teachers feel an enhanced sense of ownership in their CPD. However, emphasis should be placed on clarity of goals and the procedure whenever this model is practiced for professional development.

\section{Implications for Practice}

Based on the conclusions drawn from this study, several suggestions can be made regarding the implementation of peer observation as an instrument for CPD.

1. Firstly, considering the significance expressed by participants about peer observation in professional development, it is essential to clarify its goals and the procedures that may allow for these goals to be realized. Therefore, it is recommended that colleagues may be provided with some pre-agreed criteria or a kind of training to enable them observe each other in peer observation program. This is also aligned with the participants' comments that without a specific focus or agreement about what is to be observed, the observed teacher is unlikely to respond positively to the observer's feedback.

2. A model that advocates the peer observation for professional growth may still require careful planning to be successful. For example, many of the participants in this study felt that they would benefit from such a program in the best way if they had further training in how to use classroom observation as a basis for their own learning. Opportunities for participants to be trained to develop observational skills should therefore be an important consideration for the administration and high ups.

3. There are additional strategies that could be suggested in peer observation to minimize the sense that one's teaching is being judged or evaluated. For instance, a participant from Focus Group 1 suggested an approach in which two teachers discuss a prospective lesson plan; one teacher gives the lesson without being observed, and both meet afterwards to discuss how it went. This idea has many similarities to 'Ghost Observation', an approach outlined by the British Council (2011) that has the 
additional elements of the teacher identifying an area for development before the lesson and having this been discussed by both parties during the debrief. The British Council (2011) also recommended an approach called 'Stealing' in which a teacher observes a colleague's class looking for ideas and techniques to integrate into their own practice. Afterwards, the teacher meets with the observed colleague to discuss what they would 'steal' and why. A sense of scrutiny is minimized in this approach because the observer is explicitly identified as the learner and the observed teacher is viewed as the expert. The advantage of both approaches is that the opportunity for collaborative dialogue, considered an essential part of effective development for teachers (Murray, 2010) is maintained.

4. Finally, it is recommended that peer observation may be embedded within a broader peer coaching program. Such a step may have increased benefits for secondary school teachers. In this regard, it is suggested that in peer mentoring a novice teacher may be paired with a more experienced colleague who can provide personalized support and encouragement. This may be an effective learning tool in a professional development program because of the willingness displayed by the novice participants in the study to observe and learn from their more experienced colleagues. In addition, in such a process of peer observation, both teachers i.e. the more experienced and the less experienced may see themselves as equals and this may provide further opportunities for their mutual professional growth.

\section{Limitations}

The following are some of the limitations that may affect the scope of the study to some extent;

1. The number of participants represents a significant limitation to this study, with only 12 participants were selected to take part in the study. Their experience may not reflect the experiences of the general population.

2. The small size of the focus groups, while affording participants many opportunities to share ideas, may have also resulted in a smaller pool of ideas, may be considered a further limitation.

3. The participants were all teachers in the same educational program, meaning that their insights into how peer observation is perceived in this particular program may not be relevant (because of the diversities of the contexts) to other peer observation programs at other institutions. It is therefore difficult to identify the findings as generalizable. 


\section{Recommendations for Future Research}

It is recommended that further studies on peer observation as a tool for CPD include a larger number of participants and more focus groups to obtain a broader range of views. A greater diversity in the selected participants' professional or cultural backgrounds may lead to more enriched insights into how the practice is perceived and more generalizability of the findings.

\section{References}

Baron, R. A. (2008). The role of affect in the entrepreneurial process. Academy of management Review, 33(2), 328-340.

Beigy, A., \& Woodin, J. (1999). Developing tandem observation.

Bell, M. (2001). Supported reflective practice: a programme of peer observation and feedback for academic teaching development. International Journal for Academic Development, 6(1), 29-39.

Chamberlain, J. M., D’Artrey, M., \& Rowe, D. A. (2011). Peer observation of teaching: A decoupled process. Active Learning in Higher Education, 12(3), 189-201.

Corbin, J., \& Strauss, A. (2008). Basics of qualitative research: Techniques and procedures for developing grounded theory.

Cosh, J. (1999). Peer observation: a reflective model.

Creswell, J. W., \& Creswell, J. D. (2017). Research design: Qualitative, quantitative, and mixed methods approaches. Sage publications.

Dadds, M. (1997). Continuing professional development: nurturing the expert within. British Journal of In-service Education, 23(1), 31-38.

Day, C. (1999). Developing teachers. The challenges of lifelong learning.

Day, C., \& Sammons, P. (2013). Successful Leadership: A Review of the International Literature. CfBT Education Trust. 60 Queens Road, Reading, RG1 4BS, England.

Dewey, J. (2001). The educational situation: As concerns the elementary school. Journal of Curriculum Studies, 33(4), 387-403.

Dreyfus, H. L. (1989). The Dreyfus model of skill acquisition. Competency Based Education and Training, 181-183.

DuFour, R., DuFour, R., \& Eaker, R. (2008). Revisiting learning communities at work. Bloomington, IN: Solution Tree.

Elmore, R. F. (2004). School reform from the inside out: Policy, practice, and performance. Harvard Education Press. 8 Story Street First Floor, Cambridge, MA 02138. 
Ferrance, E. (2000). Action research. LAB, Northeast and Island Regional Education Laboratory at Brown University.

Friere, P. Pedagogy of the Oppressed (New York: Bloomsbury Academic, 2000) and bell hooks. Teaching to Transgress: Education as the Practice of Freedom, 183-202.

Fullen, B. M., Baxter, G. D., O’Donovan, B. G. G., Doody, C., Daly, L., \& Hurley, D. A. (2008). Doctors' attitudes and beliefs regarding acute low back pain management: a systematic review. Pain, 136(3), 388-396.

Gaies, S., \& Bowers, R. (1990). Clinical supervision of language teaching: the supervisor as trainer and educator. Second language teacher education, 167-181.

Global, T., \& Council, B. (2011). The Global Skills Gap: Preparing young people for the new global economy. Think Global and British Council.

Grimm, E. D., Kaufman, T., \& Doty, D. (2014). Rethinking classroom observation. Educational Leadership, 71(8), 24-29.

Guskey, T. R., \& Yoon, K. S. (2009). What works in professional development? Phi delta kappan, 90(7), 495-500.

Hammersley-Fletcher*, L., \& Orsmond, P. (2004). Evaluating our peers: is peer observation a meaningful process? Studies in higher education, 29(4), 489-503.

Harris, A. (2004). Teacher leadership and distributed leadership: An exploration of the literature. Leading and managing, 10(2), 1.

Herbart, J. F. (1896). The science of education. DC Heath \& Company.

https://www.biography.com/scholar/confucius/Retrievd on January 24, 2020

Joyce, B., \& Showers, B. (1995). Learning experiences in staff development. The developer, 3 .

Kennedy, A. (2005). Models of continuing professional development: a framework for analysis. Journal of in-service education, 31(2), 235-250.

Kennedy, C., Kools, S., \& Krueger, R. (2001). Methodological considerations in children's focus groups. Nursing Research, 50(3), 184-187.

Kohut, G. F., Burnap, C., \& Yon, M. G. (2007). Peer observation of teaching: Perceptions of the observer and the observed. College Teaching, 55(1), 19-25.

Latz, A. O., Speirs Neumeister, K. L., Adams, C. M., \& Pierce, R. L. (2008). Peer coaching to improve classroom differentiation: Perspectives from project CLUE. Roeper Review, 31(1), 27-39. 
Lewin, K. (1947). Frontiers in group dynamics: Concept, method and reality in social science; social equilibria and social change. Human relations, 1(1), 5-41.

Lincoln, Y. S., \& Guba, E. G. (1985). Naturalistic inquiry (Vol. 75). Sage.

Maxwell, J. C. (2007). The 21 irrefutable laws of leadership: Follow them and people will follow you. Thomas Nelson.

McNiff, J. (2017). Action research: All you need to know. Sage.

Nunan, D., \& Bailey, K. M. (2009). Exploring second language classroom research: A comprehensive guide. Boston, MA: Heinle, Cengage Learning.

Park, S., Oliver, J. S., Johnson, T. S., Graham, P., \& Oppong, N. K. (2007). Colleagues' roles in the professional development of teachers: Results from a research study of National Board certification.

Peery, A. B. (2004). Deep change: Professional development from the inside out. R\&L Education. Teaching and teacher education, 23(4), 368-389.

Richards, J. C., \& Farrell, T. S. C. (2005). Professional development for language teachers: Strategies for teacher learning. Ernst Klett Sprachen.

Richards, J. C., \& Lockhart, C. (1991). Teacher development through peer observation. Tesol Journal, 1(2), 7-10.

Schmoker, M. (2006). Results now: How we can achieve unprecedented improvements in teaching and learning. ASCD.

Senge, P. M., Dow, M., \& Neath, G. (2006). Learning together: new partnerships for new times. Corporate Governance: The international journal of business in society, 6(4), 420-430.

Shortland, S. (2010). Feedback within peer observation: Continuing professional development and unexpected consequences. Innovations in Education and Teaching International, 47(3), 295-304.

Stringer, E. T. (2007). Action research (3e éd.).

Sykes, G. (1983). Contradictions, ironies, and promises unfulfilled: A contemporary account of the status of teaching. The Phi Delta Kappan, 65(2), 87-93.

Tienken, C. H., \& Stonaker, L. (2007). When every day is professional development day. The Learning Professional, 28(2), 24.

Timperley, H., Wilson, A., Barrar, H., \& Fung, I. (2007). Teacher professional learning and development: Best evidence synthesis iteration. Ministry of Education.

Tomal, D. R. (2010). Action research for educators. Rowman \& Littlefield Publishers. 
Werner, J. M., \& DeSimone, R. L. (2011). Human resource development. Cengage Learning. Zwart, R. C., Wubbels, T., Bolhuis, S., \& Bergen, T. C. (2008). Teacher learning through reciprocal peer coaching: An analysis of activity sequences. Teaching and teacher education, 24(4), 982-1002. 